\title{
The improvement of Asphalt materials by adding Nano silica
}

\author{
Abdullah Abou Khadrah, Mohamed Elshrief, Marwa Sabry.
}

\begin{abstract}
---
Nanotechnology has been gradually penetrated into the field of asphalt modification. Seemingly magic effects of nanomaterial have been brought to improve the performance of asphalt. To demonstrate many of the prospective applications, researchers have conducted a series of positive and effective efforts dealing with the preparation of modified asphalt to demonstrate the mechanism of modification and the resultant improvement in performance. In this review, various nanomaterial used in asphalt modification are initially presented, followed by the methods employed to modify the asphalt with these materials and finally the effects of nanomaterial on the performance of base asphalt are presented and the modification mechanisms are discussed. Based on the current research results, the influence of preparation process parameters on the compatibility of every phase in the modified asphalt and the stability of the modified asphalt system are described. Finally, the development trend of the topic field is projected. In this study the experimental testing of Nano silica with three percentages $2 \%, 4 \%$, and $6 \%$ by the weight of asphalt were blended in asphalt binder at high temperature to exfoliate the Nano silica within the asphalt. The asphalt binder was then characterized using the AASHTO viscosity, penetration test, softening point, flash point and Marshall Test.

These types of additives of Nano-silica is increasing the viscosity at $2 \%, 4 \%$ and $6 \%$,increase the penetration by increasing the percent of Nano silica, increasing the softening point by percent of Nano
\end{abstract}

Dr. Abdullah Abou Khadrah

Faculty of engineering - Beni suef University

Egypt

Dr. Mohamed Elsherif

Faculty of engineering - Benha University

Egypt

\section{E, Marwa Sabry}

Faculty of engineering - Benha University

Egypt silica, but flash point not affected. In Marshall Test when adding $2 \%$ of Nano silica by the weight of asphalt Marshall Stabilization increased; but adding $4 \%$ the value of stabilization is smaller than it at $2 \%$ but not reached to the original sample stabilization. Adding 6\% of these additives increased Marshall Stabilization again which represented with frequent line.

\section{Introduction:}

\section{A. Asphalt materials:}

Asphalt oxidative aging is one of the prevalent causes of pavement distresses which increase pavement susceptibility to fatigue and low temperature cracking. This phenomenon is mainly studied through oxidation kinetics and through evaluating oxygen diffusivity rate into asphalt binders while oxidative aging in pavement is inevitable, application of antiaging additives shown to be an effective method in delaying oxidative aging. Such as these paper investigates the merit of application of Nano-silica as an anti-aging additive. Different percentages of Nano silica were added to neat asphalt binder. Asphalt binder was then exposed to short term oxidative aging using a rolling thin film oven (RTFO) [1]. To study the change in the chemical, rheological and morphological properties of asphalt binders in presence of Nano- silica, the AASHTO tests, Fourier transform infrared spectroscopy (FTIR) as well as SEM imaging was conducted. The FTIR study shows that Nano- silica can improve the aging resistance of the asphalt binder as reflected in lower level of carboxylic acids (observed at 1400- $1440 \mathrm{~cm}-1$ ) and sulfide (observed at $\sim 1050 \mathrm{~cm}-1$ ) in Nano silica modified specimen compared to those in nonmodified specimens. Carboxylic acids occur naturally in asphalt; however its concentration has been known to be increased significantly due to oxidative aging. This in turn reduces oxidation aging in modified asphalt. In addition, it was found that presence of Nano- silica significantly increases the complex modulus $\left(\mathrm{G}^{*}\right)$ and complex viscosity $\left(\eta^{*}\right)$ of the asphalt binder. This in turn improves pavement 
resistance to rutting. It was concluded that introduction of Nano- silica to asphalt binder can improve the anti- aging property, rutting performance and rheological properties of asphalt binder.

\section{B. The chemical composition of asphalt:}

The chemical composition of asphalt is quite complex, therefore, researchers mainly use percentages of SARA (Saturates, Asphaltene, Resin and Aromatic) to compare various asphalt binder produced from different origins. Composition of each asphalt binder is typically grouped into two categories: asphaltenes and maltenes. The latter can be further subdivided into saturates, aromatics and resins [2].

However, asphalts colloidal system may change when it is exposed to oxygen at elevated temperature causing oxidative during asphalt production and service life. Aging has been known to be one of the principal factors expediting asphalt pavement's deterioration [3]. The occurrence of asphalt binder aging is further expedited by thermal- oxidation during storage, mixing, transport and placing and compaction; this in turn negatively affects asphalt binder rheological properties causing pavement to be more susceptible to low temperature cracking [4-5]. While pavement oxidative aging is inevitable, there have been many studies to better understand the oxidation mechanisms as well as to develop new methods and additives to delay oxidative aging. Among those additives are various resins, rubbers, polymers, sulphur, metal complexes, fibers, chemical agents and Nano materials. The use of Nanomaterials has seen a tremendous development in recent years mainly due to their surface properties and their effectiveness in altering hierarchical structure of composite materials [6-7-8-9]. It has been shown that introduction of certain Nanomaterials into asphalt binder could offer a significant improvement in asphalt physical and rheological properties leading to development of Nano modified asphalt with superior performance. As such nanotechnology has been gradually incorporated into the field of modified asphalt with various kinds of Nano- materials being used to modify asphalt in recent years. Nano- silica has been widely used in polymers and asphalt binder as inorganic filler to improve the properties of polymeric and bituminous materials [10-11-12-13]. Over the last 10 years, Nano- silica has served as a promising material for designing and preparing new functional materials because of its high surface area and stability [14-1516-17].The shape and dimension of the silica particles are very desirable for application in asphalt binder mainly because the surface area of interaction is much higher than that of conventional fillers. By dispersing Nano- silica into asphalt matrix one can create polymeric Nano- composites with enhanced mechanical behavior, thermal and gas barrier properties [18-19-20] Therefore, in this study, the nano- silica was used to modify the asphalt binder. Nano- silica was added into the neat asphalt binder at concentrations of $2 \%, 4 \%$ and $6 \%$ by weight of the base asphalt binder. Rheological, chemical and morphological characterization of neat and modified asphalt binder was conducted to evaluate the performance of Nano- silica modified asphalt binder. Following sections of the paper is devoted to description of materials and test methods including materials and sample preparation, aging procedure, dynamic rheological characterization and Fourier transform infrared spectroscopy (FTIR). The results of Physical properties of asphalt binder, dynamic rheological characterization and Fourier Transform Infrared Spectroscopy (FTIR) are presented in section 3. Dynamic rheological properties of asphalt binders are investigated based on three approaches including frequency sweep, temperature sweep and shear creep. Finally, the merit of application of Nano- silica to improve anti- aging properties of asphalt binder is discussed.

\section{Materials and Test Methods:}

This section will describe various materials used in this study as well as the sources of each material and its preparation method.

\section{A- Materials and Sample Preparation:}

The base asphalt used in this study was AC 60/70 Pen grade. Asphalt binder was then blended with $2 \%$, $4 \%$ and $6 \%$ Nano- silica. The quantity of each additive was selected by weight of based asphalt binder. The mixing was conducted using an IKA®bench top high shear mixer at $4000 \mathrm{rpm}$ for 2 hours. To conduct the mixing, an aluminum can was filled with $250-260 \mathrm{~g}$ of asphalt and placed in a thermoelectric heater. When the asphalt temperature reached to $180098 \mathrm{C}$, specified amount of Nanosilica was added to the can and mixing for two hours. Using this procedure one neat sample and Nano-silica modified asphalt (NSMA) samples was produced. 
For simplicity in referring to each sample, they were named using following abbreviation: NEAT, NSMA- $2 \%$, NSMA- $4 \%$ and NSMA- $6 \%$. To ensure Nano-silica particles are dispersed uniformly within the asphalt matrix. The Scanning Electron Microscopy (SEM) images of asphalt were mainly\ used to understand the micro- structural changes of modified samples and to evaluate the matrix.

\section{B- Aging Procedure:}

All asphalt binder samples were aged by rolling thin film oven test (RTFOT) (ASTM D2872- 85) in order to simulate the hot mixing process during plant production.

\section{C- Dynamic Rheological Characterization:}

Dynamic Shear Rheometer (DSR) MCR101 from Austria Anton Par Company was used in this study to measure complex modulus and complex viscosity. The repeated shear creep test with a loading and recovery period was conducted on each specimen. The creep tests were done under two fixed shear stresses of 100 and $3200 \mathrm{~Pa}$ for 10 cycles with $1 \mathrm{~s}$ loading time and $9 \mathrm{~s}$ of recovery time at $50^{\circ} \mathrm{C}$.

\section{D- Fourier Transform Infrared Spectroscopy (FTIR):}

Fourier Transform Infrared Spectroscopy (FTIR) spectra were recorded by Jasco IRT 3000 FTIR spectrometer. Infra- red spectra can be utilized inorganic structure determination by identifying interatomic bonds in chemical compounds. Chemical bonds in different environments will absorb varying intensities and at varying frequencies. The frequencies at which there are absorptions of IR radiation referred to as peaks can be correlated directly to bonds within the material's chemical structure. Each interatomic bond may vibrate in several different motions (stretching or bending). Stretching absorptions usually produce stronger peaks than bending.

\section{Laboratory testing and results:}

\section{A- Aggregate tests:}

To make sure that this aggregate can be used in the asphalt mix or not; it should apply aggregate tests.

-ASTM C131 Standard Test Method for Resistance to Degradation of Small Size Coarse Aggregate by Abrasion and Impact in the Los Angeles Machine.

- Tests of aggregate1:

1-LOS ANGELES TEST: TABLE (1):

\begin{tabular}{|c|c|c|c|}
\hline $\begin{array}{c}\text { No; of } \\
\text { r.p.m }\end{array}$ & $\begin{array}{c}\text { Retained } \\
\text { weight }(\mathrm{gm})\end{array}$ & $\begin{array}{c}\text { Losses } \\
\text { weight }(\mathrm{gm})\end{array}$ & \%losses \\
\hline 100 & 4685 & 315 & 6.3 \\
\hline 500 & 3597 & 1403 & 28.06 \\
\hline 600 & 3568 & 1432 & 28.64 \\
\hline
\end{tabular}

2-SPECIFIC WEIGHT, ABSORPTION AND DEGRADATION: TABLE (2):

\begin{tabular}{|c|c|}
\hline 2-SPECIFIC WEIGHT, ABSORPTION AND DEGRADATION: TABLE (2): \\
\hline Total Specific Weight & $\mathbf{2 . 4 5 9 g m} \backslash \mathbf{c m 3}$ \\
\hline Saturated Specific Weight & $\mathbf{2 . 5 3 7 g m} \backslash \mathbf{c m 3}$ \\
\hline \%Absorption & $\mathbf{3 . 2 \%}$ \\
\hline \%Degradation & $\mathbf{0 . 4 \%}$ \\
\hline
\end{tabular}

- $\quad$ Tests of aggregate2:

1-LOS ANGELES TEST: TABLE (3):
\begin{tabular}{|c|c|c|c|}
\hline $\begin{array}{c}\text { No; of } \\
\text { r.p.m }\end{array}$ & $\begin{array}{c}\text { Retained } \\
\text { weight }(\text { gm) }\end{array}$ & $\begin{array}{c}\text { Losses } \\
\text { weight }(\mathbf{g m})\end{array}$ & \%losses \\
\hline $\mathbf{1 0 0}$ & $\mathbf{4 7 5 4}$ & $\mathbf{2 4 6}$ & $\mathbf{4 . 9 2}$ \\
\hline $\mathbf{5 0 0}$ & $\mathbf{3 8 2 8}$ & $\mathbf{1 1 7 2}$ & $\mathbf{2 3 . 4 4}$ \\
\hline $\mathbf{6 0 0}$ & $\mathbf{3 8 0 7}$ & $\mathbf{1 1 9 3}$ & $\mathbf{2 3 . 8 6}$ \\
\hline
\end{tabular}

2-SPECIFIC WEIGHT, ABSORPTION AND DEGRADATION: TABLE (4):

\begin{tabular}{|c|c|}
\hline Total Specific Weight & $2.554 \mathrm{gm} \backslash \mathrm{cm} 3$ \\
\hline Saturated Specific Weight & $\mathbf{2 . 5 9 6 g m} \backslash \mathrm{cm} 3$ \\
\hline \%Absorption & $1.6 \%$ \\
\hline \%Degradation & $0.6 \%$ \\
\hline
\end{tabular}

\section{B- Laboratory program design:}

The research team used the information gathered from the literature review and evaluations conducted to shape the direction of the laboratory program.

(1) The US-127 asphalt binder modified with $2 \%$ and $4 \%$ of first Nano clay (Nano clay A) by weight of asphalt binder.

(2) The US-127 asphalt binder modified with $2 \%$ and $4 \%$ of second Nano clay (Nano clay B) by weight of asphalt binder.

(3) The US-127 asphalt binder modified with $2 \%$ and $4 \%$ of Third Nano clay (Nano clay A) by weight of asphalt binder.

-Viscosity Grade bitumen's are specified by the methods described in ASTM Standard Viscosity test applied according to (AASHTO_T201-10). Viscosity Graded specifications covers bitumen (asphalt) graded by Viscosity at $60 \mathrm{C}\left(140^{\circ} \mathrm{F}\right)$. -Penetration test (Rheological properties) of asphalt binder using penetration test according to (AASHTO_T49-07). 
-Softening point test according to (AASHTO_T5309)

Flash point test according to (AASHTO T 73 and ASTM D 93).

Marshall TEST according to (AASHTO_T48-06).

\section{C- Physical Properties of Asphalt Binder:}

The effect of Nano- silica modification on the conventional 128 asphalt binder rheological properties can be seen in table (5) and table (6). It can be observed that there is an increase in penetration, increase in viscosity and increase in softening point, but flash point not affected when Nano- silica was introduced to the asphalt binder. It was observed that all Nano- modified asphalt samples had higher penetration, higher viscosity, higher softening point and constant flash point than original asphalt. This in general can lead to improvement in the asphalt binder stiffness and flexibility. However, the result of Marshall Test showed a hesitated increase in the presence of Nano silica which seen in table (7).

-TABLE (5): RESULTS OF INCREASING PERCENT WHEN ADDING NANO SILICA OF (2\%-4\%-6\%):

\begin{tabular}{|c|c|c|c|}
\hline sample & $\begin{array}{c}\text { Additives } \\
\mathbf{( 2 \% )}\end{array}$ & $\begin{array}{c}\text { Additives } \\
\mathbf{( 4 \% )}\end{array}$ & $\begin{array}{c}\text { Additives } \\
\mathbf{( 6 \% )}\end{array}$ \\
\hline viscosity & $27.7 \%$ & $33.9 \%$ & $74.8 \%$ \\
\hline Penetration & $3.5 \%$ & $8.9 \%$ & $25 \%$ \\
\hline $\begin{array}{c}\text { Softening } \\
\text { point }\end{array}$ & $4.4 \%$ & $8.9 \%$ & $15.5 \%$ \\
\hline Flash point & $0 \%$ & $0 \%$ & $0 \%$ \\
\hline
\end{tabular}

TABLE (6): RESUltS IN VALUE OF ADDING NANO SILICA OF (2\%$4 \%-6 \%)$

\begin{tabular}{|c|c|c|c|c|}
\hline sample & $\begin{array}{c}\text { Original } \\
\text { sample }\end{array}$ & $\begin{array}{c}\text { Additives } \\
(\mathbf{2 \%})\end{array}$ & $\begin{array}{c}\text { Additives } \\
\mathbf{( 4 \% )}\end{array}$ & $\begin{array}{c}\text { Additives } \\
\mathbf{( 6 \% )}\end{array}$ \\
\hline viscosity & 310 & 396 & 415 & 542 \\
\hline $\begin{array}{c}\text { Penetration } \\
(\mathbf{1} \backslash 10 m m)\end{array}$ & 56 & 58 & 61 & 70 \\
\hline $\begin{array}{c}\text { Softening } \\
\text { point }\end{array}$ & 45 & 47 & 49 & 52 \\
\hline Flash point & +270 & +270 & +270 & +270 \\
\hline
\end{tabular}

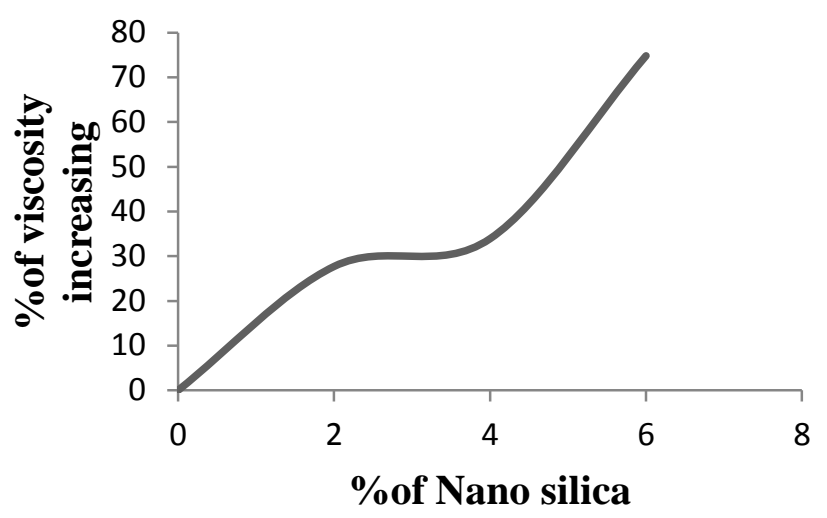

CHART (1)

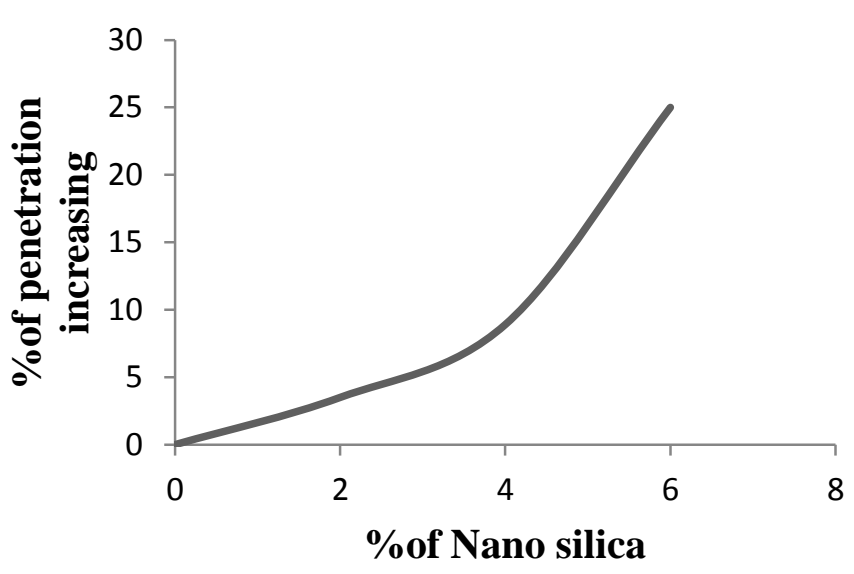

CHART (2)



CHART (3) 
Proc. of the Third Intl. Conf. on Advances in Civil, Structural and Construction Engineering - CSCE 2015

Copyright (C) Institute of Research Engineers and Doctors, USA .All rights reserved.

ISBN: 978-1-63248-079-8 doi: 10.15224/ 978-1-63248-079-8-59

TABLE (7): RESULTS OF ADDING NANO SILICA OF (2\%-4\%-6\%):

(MARSHALL TEST):

\begin{tabular}{|c|c|c|c|c|c|c|c|c|}
\hline & \multicolumn{2}{|c|}{ Original sample } & \multicolumn{2}{|c|}{ Additives 2\% } & \multicolumn{2}{|c|}{ Additives 4\% } & \multicolumn{2}{|c|}{ Additives 4\% } \\
\hline Sample No; & 1 & 2 & 3 & 4 & 5 & 6 & 7 & 8 \\
\hline W1 & 1198 & 1200 & 1208 & 1195 & 1197 & 1197 & 1199 & 1202 \\
\hline W2 & 1208 & 1211 & 1212 & 1203 & 1208 & 1205 & 1208 & 1209 \\
\hline W3 & 663 & 665 & 673 & 663 & 664 & 667 & 671 & 666 \\
\hline $\mathbf{V}$ & 545 & 545 & 539 & 540 & 544 & 538 & 537 & 543 \\
\hline G.S & 2.198 & 2.19 & 2.241 & 2.213 & 2.200 & 2.225 & 2.233 & 2.214 \\
\hline G.S avg & \multicolumn{2}{|c|}{2.19} & \multicolumn{2}{|c|}{2.227} & \multicolumn{2}{|c|}{2.213} & \multicolumn{2}{|c|}{2.223} \\
\hline$\% \mathrm{e}$ & 8.4 & 8.4 & 10.7 & 9.7 & 8.8 & 9.5 & 8.9 & 9.8 \\
\hline R1 & 0.9 & 1.02 & 1.25 & 1 & 1.1 & 1 & 1.1 & 1.1 \\
\hline $\mathbf{F}$ & 2354 & 2666 & 3267 & 2615 & 2875 & 2615 & 2875 & 2875 \\
\hline C.F & 0.93 & 0.93 & 0.93 & 0.93 & 0.93 & 0.93 & 0.93 & 0.93 \\
\hline Stabilization(Ib) & 2189 & 2185 & 3038 & 2432 & 2674 & 2432 & 2674 & 2674 \\
\hline Stabilization avg(Ib) & \multicolumn{2}{|c|}{2187} & \multicolumn{2}{|c|}{$\frac{1}{2735}$} & \multicolumn{2}{|c|}{2553} & \multicolumn{2}{|c|}{2674} \\
\hline$\%$ stabilization & \multicolumn{2}{|c|}{$0 \%$} & \multicolumn{2}{|c|}{$25 \%$} & \multicolumn{2}{|c|}{$16.7 \%$} & \multicolumn{2}{|c|}{$22.3 \%$} \\
\hline Flow(1/100") & 9 & 16.5 & 10 & 9.6 & 11 & 10.6 & 12.5 & 12.3 \\
\hline
\end{tabular}

R1=Marshall Stability reading.

$\mathrm{F}=$ Failure load (bound).

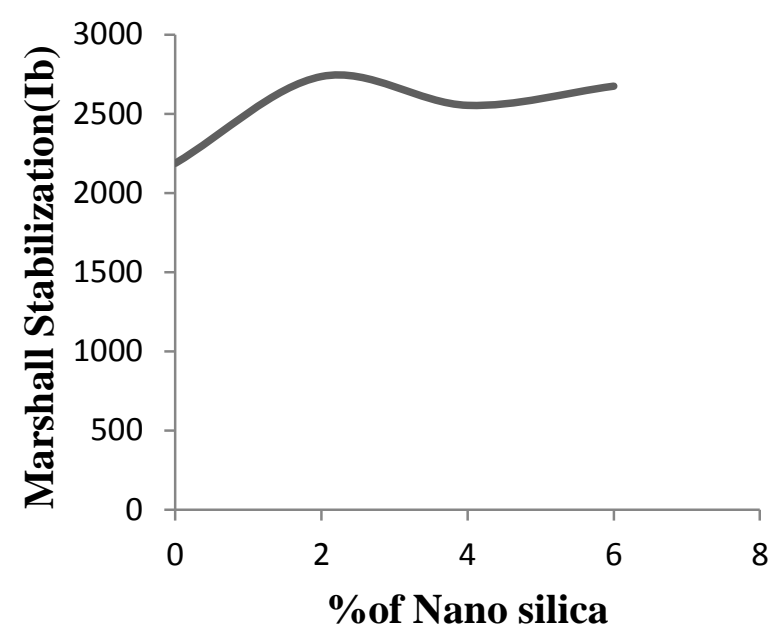

$\mathrm{W} 1=$ Weight of sample in air.

CHART (4)

W2=Weight of sample after submerged in water for 2 minutes.

W3=Weight of sample in water.

$\mathrm{V}=$ Volume of sample.

G.S=Specific gravity of sample.

G.S avg= Average specific gravity of sample.

$\mathrm{e}=$ percent of air voids.
C.F=Correction factor.

\section{Conclusion:}

These types of additives of Nano-silica improved the viscosity, penetration, softening point and Marshall Stabilization of bitumen according to the percent, but flash point not affected:

-Adding $2 \%$ of Nano silica increased viscosity by $27.7 \%$, increase penetration by $3.5 \%$, increase softening point by $4.4 \%$ and increase Marshall Stabilization by $25 \%$.

- Adding $4 \%$ of Nano silica increased viscosity by $33.9 \%$, increase penetration by $8.9 \%$, increase softening point by $8.9 \%$ and increase Marshall Stabilization by $16.7 \%$.

- Adding $6 \%$ of Nano silica increased viscosity by $74.8 \%$, increase penetration by $25 \%$ increase softening point by $15.5 \%$, and increase Marshall Stabilization by $22.3 \%$. 


\section{Key words:}

1-RTFO: Rolling thin film oven.

2-FTIR: Fourier transforms infrared spectroscopy.

3- $\eta^{*}$ : Complex viscosity.

4-(G*): Complex modulus.

5-SARA: Saturates, Asphaltene, Resin and Aromatic.

6- NSMA: Nano-silica modified asphalt.

\section{-References:}

[1] Ferhad Zafari, Mohammad Rahi, Nazanin Moshtagh, Hossien Nazockdast. The improvement of Bitumen Properties by adding Nano silica. Study of civil Engineering and Architecture (SCEA) volume3, 2014.

[2] Petersen, J. C. (1984). "Chemical composition of asphalt as related to asphalt durability: state of the art." Transportation Research Record, 13-30.

[3] Lu, X., and Isacsson, U. (1998). " Chemical and rheological evaluation 248 of ageing properties of SBS polymer modified bitumen's." Fuel, 77(9-10), 961-972.

[4] Lu, X., and Isacsson, U. (2002). "Effect of ageing on bitumen chemistry and rheology." construction and building materials, 16(1), 15-22.

[5] Gawel, I., and Baginska, K. (2004). " Effect of Chemical Nature on the Susceptibility of Asphalt to Aging." Petroleum Science and Technology, 22(9-10), 1261-1271.

[6] You, Z., Mills-Beale, J., Foley, J. M., Roy, S., Odegard, G. M., Dai, Q., and Goh, S. W. (2011). " Nano clay-modified asphalt materials: Preparation and characterization." construction and building materials", 25(2), 1072-1078.

[7] Yao, H., You, Z., Li, L., Shi, X., Goh, S. W., Mills-Beale, J., and Wingard, D. (2012b). " Performance of asphalt binder blended with non-modified and polymer-modified Nano clay". Construction and building materials, 35(0), 159-170.

[8] Onochie, A., Fini, E., Yang, X., Mills-Beale, J., and You, Z. (2013). "Rheological characterization of Nano particle based biomodified binder." Transportation Research Board" Washington D.C.

[9] Fini, E. (2013). " Investigating Nano-particle based bio modified binder." Nanotechnology: Properties of Nanomaterial's, S. Sinha, and N. K. Navani, eds., Stadium Press LLC.

[10] Zhou, Z. A., Xu, Z., Masliyah, J. H., and Czarnecki, J 282. (1999). " Coagulation of bitumen with fine silica in model systems." Colloids and Surfaces A: Physicochemical and Engineering Aspects", 148(3), 199-211.

[11] Hu, Y.H., Chen, C.-Y., and Wang, C.-C. (2004). "Viscoelastic properties and thermal degradation kinetics of silica/PMMA Nano composites." Polymer Degradation and Stability, 84(3), 545-553.

[12] Cheng, C.-F., Cheng, H.-H., Cheng, P.-W., and Lee, Y.-J. (2006). "Effect of Reactive Channel Functional Groups and Nano porosity of Nano scale Mesoporous Silica on Properties of Polyimide Composite." Macromolecules,39(22), 7583-7590.

[13] Liu, C.-H., and Pan, C.-Y. (2007). " Grafting polystyrene onto silica nanoparticles via RAFT polymerization." Polymer, 48(13), 3679-3685.

[14] Senff, L., Labrincha, J. A., Ferreira, V. M., Hotza, D., and Repette, W. L. (2009). "Effect of Nano-silica on rheology and fresh properties of cement pastes and mortars." construction and building materials, 23(7), 24872491.

[15] Zhang, M.-H., and Islam, J. (2012). "Use of Nano-silica to reduce setting time and increase early strength of concretes with high volumes of fly ash or slag." Construction and building materials, 29(0), 573-580.

[16] Kong, D., Du, X., Wei, S., Zhang, H., Yang, Y., and Shah, S. P. (2012). " Influence of Nano-silica agglomeration on microstructure and properties of the hardened cement based materials." construction and building materials, 37(0), 707-715.

[17] Singh, L. P., Karade, S. R., Bhattacharyya, S. K., Yousuf, M.M., and Ahalawat, S. (2013)." Beneficial role of Nano silica in cement based materials - A review." construction and building materials", 47(0), 1069-1077.

[18] LeBaron, P. C., Wang, Z., and Pinnavaia, T. J. (1999)." Polymerlayered silicate Nano composites: an overview." Applied Clay Science, 15(1-2), 11-29.

[19] Sinha Ray, S., and Okamoto, M. (2003). " Polymer/layered silicate Nano composites: a review from preparation to processing." Progress in Polymer Science, 28(11), 15391641.

[20] Yao, H., You, Z., Li, L., Lee, C., Wingard, D., Yap, Y., Shi, X., and Goh, S. (2012a)." Rheological Properties and Chemical Bonding of Asphalt Modified with Nanosilica." Journal of Materials in Civil Engineering, 25(11), 1619-1630. 